\title{
HEPATITIS AND PNEUMONITIS DURING ADALIMUMAB THERAPY IN CROHN'S DISEASE: mind the histoplasmosis!
}

\author{
Bruno do Valle PINHEIRO1', Áureo de Almeida DELGADO² and \\ Julio Maria Fonseca CHEBLI ${ }^{3}$
}

\begin{abstract}
Context - Tumor necrosis factor-alpha (TNF- $\alpha$ ) inhibitor therapy plays a pivotal role in the management of moderate to severe inflammatory bowel disease. Because of the role of TNF- $\alpha$ in the host defenses, anti-TNF therapy has been associated with an increase the risks of granulomatous infections. Objective - To report the first case of adalimumab-associated invasive histoplasmosis presenting as an acute hepatitis-like syndrome and febrile pneumonitis in a patient with Crohn's disease. Method - Case report of a patient with progressive histoplasmosis confirmed by percutaneous fine needle aspiration biopsy lung and urine Histoplasma antigen. Results - We present the case of a young man with CD who developed pneumonia and acute hepatitis-like features caused by Histoplasma capsulatum infection during adalimumab therapy. To the best of our knowledge, this acute hepatitis-like manifestation has never been reported as a presentation of the histoplasmosis in patients with Crohn's disease. Conclusions - This case underscores the potential risk for serious infection that may arise in this setting and should alert clinicians to the need to consider the histoplasmosis diagnosis in patients presenting with acute hepatitis-like syndrome associated with prolonged febrile illness or pneumonitis during therapy with anti-TNF- $\alpha$ antibodies.
\end{abstract}

HEADINGS - Crohn disease. Tumor Necrosis Factor-alpha. Adalimumab. Histoplasmosis. Hepatitis.

\section{INTRODUCTION}

Tumor necrosis factor-alpha (TNF- $\alpha)$ inhibitors are effective in treating many inflammatory disorders and are frequently used in Crohn's disease $(\mathrm{CD})^{(7)}$. Because of the role of TNF- $\alpha$ in the host defenses, particularly in granuloma formation, these therapies increase the risks of granulomatous infections, notably tuberculosis (the most common), but also other mycobacterial and invasive fungal infections ${ }^{(2)}$. Histoplasmosis is a ubiquitous endemic mycosis that is usually asymptomatic, but occasionally results in severe disease. It is the most common invasive fungal infection in individuals on TNF- $\alpha$ inhibitor therapy ${ }^{(9)}$.

Histoplasmosis and its causative agent, Histoplasma capsulatum, are found worldwide, but especially in North and Central America. The fungus is acquired through inhalation of mycelia fragments and micro conidia, notably from contaminated soil from bird or bat guano. The highest concentration of the fungus often is in abandoned buildings and caves. Infection is commonly associated with exposure to bird roosts as well as the high-risk activities (e.g., demolition of old buildings, cleaning chicken coops, and spelunking) in endemic areas ${ }^{(3)}$.
Of note, the majority of patients who develop disseminated histoplasmosis are immunosuppressed (i.e., AIDS, hematologic malignancies, congenital Tcell deficiencies, solid organ transplantation, therapy with TNF- $\alpha$ inhibitors) or are at the extremes of age $^{(2,9)}$. Cases of disseminated illness occurring shortly after initiation of therapy with TNF- $\alpha$ inhibitors could represent worsening of smoldering infection exacerbated by recently intensified immunosuppression, or newly acquired infection as well as reactivation ${ }^{(3,10)}$.

Healthcare professionals must be alert to the possibility of this diagnosis, because delay in diagnosis and treatment increases the risk of poor outcomes, including death. We present the case of a young man with CD who developed pneumonia and acute hepatitis-like features caused by Histoplasma capsulatum infection during adalimumab therapy. To the best of our knowledge, this acute hepatitis-like manifestation has never been reported as a presentation of the histoplasmosis in patients with CD. This case report was approved by the ethics committee of our center. Informed consent to publish the report was obtained from patient. The authors have followed the ethical adherence guidelines.

Declared conflict of interest of all authors: none

Divisão de Pneumologia, Departamento de Medicina, Hospital da Universidade Federal de Juiz de Fora, MG: ${ }^{2}$ Departamento de Medicina, Hospital Santa Casa, Juiz de Fora, MG, Brasil; ${ }^{3}$ Divisão de Gastroenterologia, Departamento de Medicina, Centro de Doenças Inflamatórias Intestinais, Hospital da Universidade Federal de Juiz

de Fora, MG, Brasil.
Supportive foundations: Julio Maria Fonseca Chebli is recipient of a grant from CNPq and FAPEMIG, Brasil.

Correspondence: Julio Maria Fonseca Chebli. Rua Maria José Leal, 296 - 36036-247 - Juiz de Fora, MG, Brasil. E-mail: chebli@globo.com 


\section{Case report}

A 34-year-old white man was admitted to our department in November 2012 complaining of malaise, mild shortness of breath, cough, fever, sweats, muscle aches, and headache over the past 4 weeks. In the previous 2 weeks, he had undergone outpatient antibiotic treatment (levofloxacin) without any apparent effect. His current treatment included monotherapy with adalimumab.

The patient was diagnosed with ileocolonic, nonstricturing, nonpenetrating CD by performing ileocolonoscopy, histology, and a follow-through small bowel examination 10 years before presentation. At that time, the patient's condition improved with conventional treatment with mesalazine and steroids, but he soon developed steroiddependent disease. He was then treated successfully with azathioprine (AZA) (2.5 mg/kg body weight), and steroids were gradually tapered. The patient remained in clinical remission on AZA for 8 years subsequently. In October 2010 , he experienced a flare of disease accompanied by arthritis of the knees and elbows regardless of the AZA therapy. He was started on induction treatment with adalimumab (160 $\mathrm{mg} / 80 \mathrm{mg}$ at weeks 0 and 2) followed by maintenance with $40 \mathrm{mg}$ every other week. Induction therapy resulted in a notable improvement of the clinical manifestations. Thus, adalimumab treatment was maintained over the subsequent 23 months, and the patient remained asymptomatic until 1 month before admission.

His vital signs on admission were temperature $38.1{ }^{\circ} \mathrm{C}$, pulse $102 / \mathrm{min}$, respiratory rate 28 breaths/min, blood pressure $120 / 70 \mathrm{mmHg}$, and arterial oxygen saturation $94 \%$ breathing room air. The physical examination yielded discrete hepatosplenomegaly. Laboratory tests at this time showed normal complete blood count, alkaline phosphatase $490 \mathrm{U} / \mathrm{L}$ (4x LSN), bilirubin $1.8 \mathrm{mg} / \mathrm{dL}$, albumin $2.8 \mathrm{~g} / \mathrm{dL}$, international normalized ratio (INR) 1 , alanine transaminase (ALT) $880 \mathrm{U} / \mathrm{L}$, aspartate transaminase (AST) $625 \mathrm{U} / \mathrm{L}$, erythrocyte sedimentation rate $56 \mathrm{~mm} / \mathrm{h}$, and C-reactive protein $45 \mathrm{mg} / \mathrm{L}$. Evaluation for specific antibodies in serum, including IgM anti-HAV, HBsAg, anti-HBs, anti-HBc, anti-HCV, HCV RNA, IgM anti-Epstein Barr virus, ANA, and SMA, was unremarkable, and polymerase chain reaction (PCR) for cytomegalovirus was negative. In addition, the stool and blood culture results were negative for infection.

Abdominal ultrasound showed hepatosplenomegaly and non-dilated bile ducts. A chest radiograph revealed a small, poorly defined area of airspace consolidation in the right upper lobe (Figure 1), confirmed by a computed tomography (CT) scan, which also demonstrated a larger area of ground glass attenuation (Figure 2). A purified protein derivative (PPD) skin test was negative. In addition, sputum examinations for microorganisms, including acid-fast bacilli and fungi, were repeatedly negative. A bronchoscopy showed hyperemia of the right bronchial tree, but microscopic examination and bronchoalveolar lavage (BAL) cultures were negative for mycobacteria and fungi. A CT-guided percutaneous needle aspiration biopsy was conducted (Figure 3), and the histopathologic examination of the tissue stained by methe-

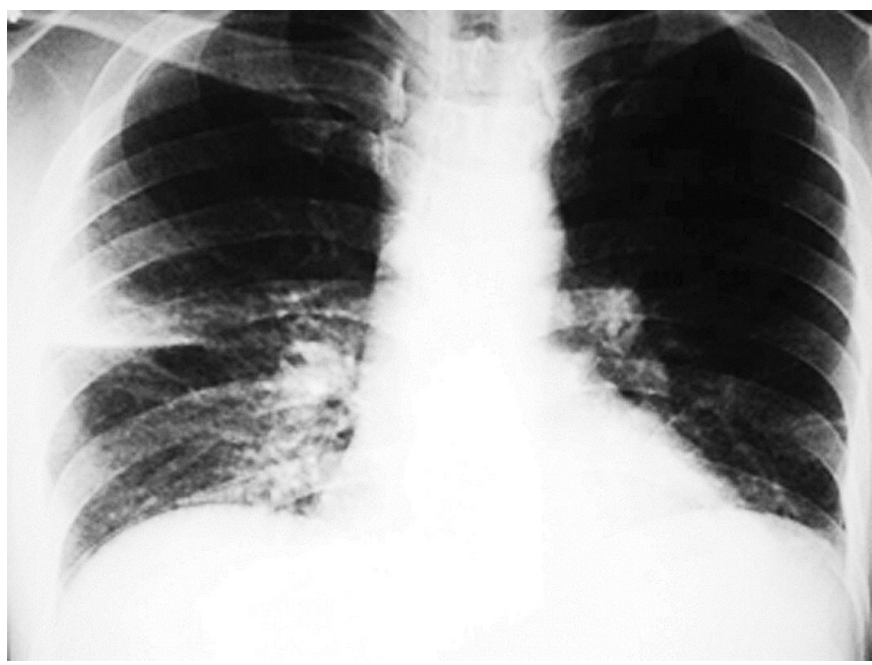

FIGURE 1. Posteroanterior chest radiograph discloses an area of inhomogeneous consolidation in the right upper lobe

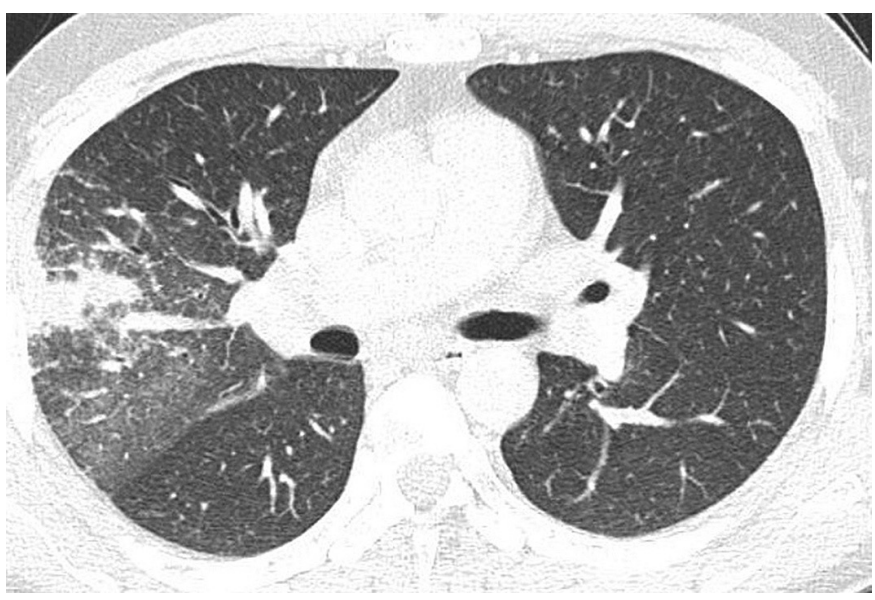

FIGURE 2. CT section through the middle lungs shows a peripheral ill-defined airspace consolidation surrounded by an area of ground-glass opacification

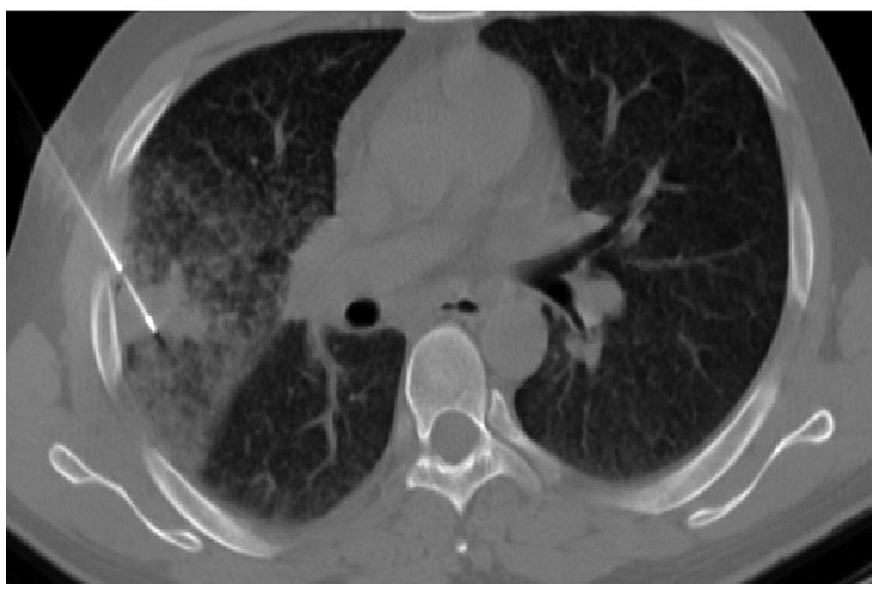

FIGURE 3. CT scan performed during the percutaneous needle aspiration biopsy of the area with airspace consolidation 
namine- silver demonstrated yeasts resembling Histoplasma (Figure 4). His urine Histoplasma antigen and Histoplasma complement fixation titers $(1: 128)$ were also positive. The retrospective evaluation of the patient's epidemiological history revealed a possible exposure to Histoplasma (he had cleaned a granary inhabited by bats).

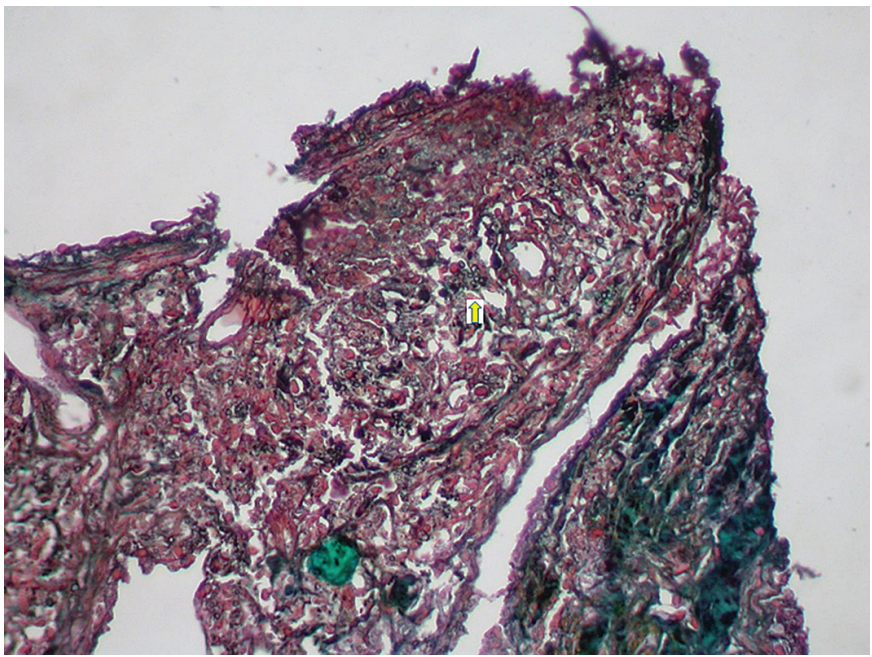

FIGURE 4. Methenamine silver-stained section of lung tissue ("400) shows large numbers of small, uniform, buddin g yeasts suggestive of Histoplasma capsulatum (yellow arrows)

Adalimumab was held, and amphotericin B treatment was initiated at a dosage of $60 \mathrm{mg} /$ day and sustained for 12 days. The fever and the constitutional symptoms improved within a few days, and the serum aminotransferase levels quickly declined. The patient was discharged receiving itraconazole, $200 \mathrm{mg}$ twice daily for 6 months. Therapy with AZA was restarted two months later while the patient remained on itraconazole. He is currently asymptomatic on AZA without fungal prophylaxis. Serum AST and ALT levels remain normal, and repeated urine and plasma Histoplasma antigens remain negative 8 months after the initial infection.

\section{DISCUSSION}

This report highlights a case of progressive histoplasmosis with acute hepatitis-like syndrome and pneumonitis following adalimumab maintenance therapy in a patient with $C D$.

The clinical manifestations of disseminated histoplasmosis as well as the timing of presentation vary based on host immunodeficiency and the degree of exposure to the fungus ${ }^{(4)}$. Individuals may present shortly after the exposure or years later and may experience asymptomatic periods alternating with symptomatic relapses. Histoplasmosis occurring in patients with inflammatory bowel disease taking anti-TNF- $\alpha$ therapy has been previously reported in the literature ${ }^{(1,2,9)}$. The majority of patients in these reports had respiratory symptoms associated with fever, malaise, diaphoresis, headache, fatigue, hepatosplenomegaly, and pancytopenia. Hepatic involvement is suggested by the presence of modest elevations in serum aminotransferases, alkaline phosphatase, and/or bilirubin. Overwhelming infection manifested by multiple organ dysfunction, obtundation, and coagulopathy can occur in severely immunodeficient subjects such as those receiving immunosuppressive drugs ${ }^{(4)}$. However, markedly elevated serum aminotransferase values suggestive of acute hepatitis have not been previously reported in patients with $\mathrm{CD}$ presenting with disseminated histoplasmosis during anti-TNF- $\alpha$ therapy. Interestingly, granulomatous hepatitis caused by Histoplasma capsulatum has been reported in patients with human immunodeficiency virus ${ }^{(6)}$. Although liver biopsy was not performed in the present case, it is possible to speculate that the acute hepatitis-like presentation could be explained by the presence of extensive hepatic granulomatoses caused by disseminated histoplasmosis.

The diagnosis of histoplasmosis in immunosuppressed individuals is often delayed because of the overlap of symptoms with other more prevalent infectious complications such as tuberculosis and cytomegalovirosis ${ }^{(1,5)}$. Blood, sputum, or tissue specimen (e.g., bone marrow) culture remains the "gold standard" for diagnosis and should be obtained according to the clinical presentation ${ }^{(8)}$. Nonetheless, cultures can take 1-6 weeks to grow. Complement-fixation antibodies are considered presumptive evidence of active or recent infection if there is a single titer $\geq 1: 32^{(12)}$. However, the results are often delayed for $2-6$ weeks ${ }^{(5)}$. On the other hand, the Histoplasma antigen detection on urine, serum, or bronchoalveolar lavage fluid is a sensitive and rapid method and may be useful in the diagnosis of histoplasmosis, primarily in patients who are severely $\mathrm{ill}^{(4)}$. Curiously, antigen testing sensitivity is higher in immunosuppressed individuals with disseminated disease, although a negative result does not rule out an active infection ${ }^{(8)}$. Serial antigen testing monitoring in a patient with initial positivity may be used to follow therapy response and identify recurrence ${ }^{(11,12)}$. If histoplasmosis is diagnosed promptly, antifungal therapy is highly effective. In this setting, discontinuation of TNF- $\alpha$ inhibitor therapy is important, although little evidence exists to determine when and how immunosuppressive therapy can be resumed ${ }^{(13)}$. While some authors reported the successful (i.e., without relapse of histoplasmosis) resumption of anti-TNF- $\alpha$ therapy in patients who ended a complete antifungal course, long-term antifungal prophylaxis may be needed if anti-TNF- $\alpha$ treatment is reinitiated ${ }^{(2,13)}$. It is important highlight that in our patient the combination therapy with adalimumab and azathioprine might have exacerbated the secondary immunossupression, thus rendering the patient more susceptible the fungus infection. Is well known that azathioprine antagonizes purine metabolism and may inhibit synthesis of DNA, RNA, and proteins. Hence, it suppresses the proliferation of $\mathrm{T}$ and $\mathrm{B}$ lymphocytes ${ }^{(14)}$.

Clinicians, particularly those involved with inflammatory bowel disease management, must be aware that the evaluation of patients on anti-TNF- $\alpha$ therapy presenting with febrile illnesses accompanied by acute hepatitis features should include tests to exclude histoplasmosis, mainly in persons 
from endemic areas or with a history of possible exposure to fungus. In addition, individuals receiving anti-TNF- $\alpha$ therapy should be advised about avoiding exposure and reporting early symptoms suggestive of infection.

\section{CONCLUSIONS}

In summary, the possibility of histoplasmosis must be strongly considered in patients receiving TNF- $\alpha$ inhibitor therapy that develop nonspecific systemic symptoms such as progressive febrile illness, undiagnosed pneumonia, and acute hepatitis-like syndrome. Empirical treatment with amphotericin should be considered while awaiting the results of diagnostic tests for patients with suspicious epidemiologic and clinical features. This approach may decrease the mortality of this life-threatening infection.

Pinheiro BV, Delgado AA, Chebli JMF. Hepatite e pneumonite durante terapia com adalimumabe na doença de Crohn: lembre-se da histoplasmose! Arq Gastroenterol. 2014,51(1):73-6.

RESUMO - Contexto - Terapia com inibidor do fator de necrose tumoral-alfa (TNF- $\alpha$ ) desempenha papel fundamental no tratamento da doença inflamatória intestinal moderada a grave. Por causa do papel do TNF- $\alpha$ na defesa do hospedeiro, a terapia anti-TNF associa-se com um aumento do risco de infecções granulomatosas. Objetivos - Relatar o primeiro caso de histoplasmose invasiva associada ao adalimumabe apresentando-se como uma síndrome de hepatite aguda e pneumonite febril em um paciente com doença de Crohn (DC). Métodos - Relato de caso de um paciente com histoplasmose progressiva confirmada por biopsia pulmonar obtida por aspiração percutânea com agulha fina e pela pesquisa do antígeno do Histoplasma na urina. Resultados - Nós apresentamos o caso de um homem jovem com DC que desenvolveu pneumonia e características de hepatite aguda causadas pela infecção por Histoplasma capsulatum durante terapia com adalimumabe. No melhor de nosso conhecimento, esta manifestação tipo hepatite aguda não foi previamente relatada como apresentação da histoplasmose em pacientes com DC. Conclusões - Este caso referenda o potencial risco para infecções graves que podem surgir neste contexto clínico e deve alertar os médicos para a necessidade de considerar o diagnóstico de histoplasmose em pacientes que apresentem com síndrome de hepatite aguda associada à doença febril prolongada ou à pneumonite durante tratamento com anticorpos anti-TNF- $\alpha$.

DESCRITORES - Doença de Crohn. Fator de Necrose Tumoral-alfa. Adalimumabe. Histoplasmose. Hepatite.

\section{REFERENCES}

1. Dotson JL, Crandall W, Mousa H, Honegger JR, Denson L, Samson C, Cunningham D, Balint J, Dienhart M, Jaggi P, Carvalho R. Presentation and outcome of histoplasmosis in pediatric inflammatory bowel disease patients treated with antitumor necrosis factor alpha therapy: a case series. Inflamm Bowel Dis. 2011; 17:56-61

2. Hage CA, Bowyer S, Tarvin SE, Helper D, Kleiman MB, Wheat J. Recognition, diagnosis, and treatment of histoplasmosis complicating tumor necrosis factor blocker therapy. Clin Infect Dis. 2010;50:85-92.

3. Hage CA, Wheat LJ, Loyd J, Allen SD, Blue D, Knox KS. Pulmonary histoplasmosis. Semin Respir Crit Care Med. 2008;29:151-65.

4. Kauffman CA. Histoplasmosis: a clinical and laboratory update. Clin Microbiol Rev. 2007;20:115-32.

5. Kauffman CA. Diagnosis of histoplasmosis in immunosuppressed patients. Curr Opin Infect Dis. 2008;21:421-5.

6. Lizardi-Cervera J, Soto Ramírez LE, Poo JL, Uribe M. Hepatobiliary diseases in patients with human immunodeficiency virus (HIV) treated with non highly active anti-retroviral therapy: frequency and clinical manifestations. Ann Hepatol. 2005;4:188-91.

7. Peyrin-BirouletL, Fiorino G, Buisson A, Danese S. First-line therapy in adult Crohn's disease: who should receive anti-TNF agents? Nat Rev Gastroenterol Hepatol. 2013; 10:345-51.
8. Swartzentruber S, Rhodes L, Kurkjian K, Zahn M, Brandt ME, Connolly P, Wheat LJ. Diagnosis of acute pulmonary histoplasmosis by antigen detection. Clin Infect Dis. 2009;49:1878-82.

9. Tsiodras S, Samonis G, Boumpas DT, Kontoyiannis DP. Fungal infections complicating tumor necrosis factor- $\alpha$ blockade therapy. Mayo Clin Proc. 2008;83:181-94

10. Wallis RS, Broder MS, Wong JY, Hanson ME, Beenhouwer DO. Granulomatous infectious diseases associated with tumor necrosis factor antagonists. Clin Infect Dis. 2004;38:1261-5.

11. Wheat LJ. Improvements in diagnosis of histoplasmosis. Expert Opin Biol Ther. 2006;6:1207-21.

12. Wheat LJ, French ML, Kohler RB, Zimmerman SE, Smith WR, Norton JA, Eitzen HE, Smith CD, Slama TG. The diagnostic laboratory tests for histoplasmosis: analysis of experience in a large urban outbreak. Ann Intern Med 1982;97:680-5.

13. Wood KL, Hage CA, Knox KS, Kleiman MB, Sannuti A, Day RB, Wheat LJ, Twigg HL 3rd. Histoplasmosis after treatment with anti-tumor necrosis factor-alpha therapy. Am J Respir Crit Care Med. 2003;167:1279-82.

14. Ribeiro TCR, Chebli LA, Gaburri PD, Chebli JMF. Azathioprine in ulcerative colitis: Why, when, how and how long to use it. Drug Development Research. 2011;72:733-8.

Received 9/9/2013. Accepted 28/10/2013 